\title{
VII. Extract from a memoir on the steeping of wool, and on the influence of its different states on dyeing. Read in the French National Institute
}

\section{M.J.L. Roard}

To cite this article: M.J.L. Roard (1805) VII. Extract from a memoir on the steeping of wool, and on the influence of its different states on dyeing. Read in the French National Institute, Philosophical Magazine Series 1, 23:89, 42-51, DOI: 10.1080/14786440508562477

To link to this article: http://dx.doi.org/10.1080/14786440508562477

曲 Published online: 18 May 2009.

Submit your article to this journal $\pi$

Џll Article views: 2

Q View related articles $\llbracket$ 


\section{$\left[\begin{array}{ll}42 & ]\end{array}\right.$}

VII. Extract frem a Memoir on the Steoping of Wool, and on the Influence of its different States on Dyeing. By M. J. L. RoARD, Director of the Dyeing Establishment in the Imperial Manufactories. Read in the French $\mathrm{Na}$ tional Insiitute*.

Norit

Motwithstanding the labours of Dufay, of Hellot, of Chaptal and Berthollet, dyeing still presents a great number of problems, which are difficult to be resolved, owing to the number and variety of its agents. Besides the effects produced by the nature of the primary substances, by the action of water, of air, of caloric, and by the degree of attraction of the colouring principles for vegetable and animal substances, differences which exist in the state of the substances to be dyed occasion very remarkable alterations. M. Roard, who is charged with the superintendance of the dye-houses belonging to the imperial manufactories, has constantly observed that wools of various qualities, subjected to the same experiments, were coloured in a manner more or less intense, whenever he was desirous of forming a comparison between them. These differences in the degree of affinity for the colouring particles are owing to a modification of the wool, of which he intends to treat in another memoir.

The effects which particularly excited his astonishmont were those presented by wools perfectly alike in their external qualities, which assumed in the same vat very different colours. It was of the greater importance to inquire into the cause of this difference, as dyeing, whose influence over many of the arts is so powerful, is the basis of the manufactories of tapestry; and as the shightest errop in the production of a colour renders it totally useless and unserviceable. This strictness in the choice of colours is in an especial manner observed in the mamufactory of the Gobelins. The zeal and the exertions of M. Guillatmot, and his indefatigable perseverance in destroying deep-rooted prejudices, have brought that establishment to such a degree of splendour and perfection, that the pictares of the most celebrated painters are transferred to its productions in a manner equally accurate and astonishing. The execution of the tints destined for that manufacture is at present attended with the greater difficulties, because, instead of

- From the Annales de Chimie, No. 158.

operating, 
operating, as formerly, with a series of colours taken as it were at random, it is necessary to find precisely the shade required, to follow the insensible gradation from light to dark through an harmonious succession of thirty or forty colours. But how can a dyer, however he may be accustomed to all the operations of this kind, be sure of obtain ing invariable results, when, besides a multitude of well known causes, minute differences in the degree of twisting alter the affinity of the light, and when the least mixture in the substances to be dyed causes a considerable variation in the affinity for the colouring principle? Previous experimeits made on the wool of animals in different states, caused M. Roard to imagine that a more extensive investigation of the subject would make him acquainted with the cause of the changes he had before observed.

M. Tessier, to whom agriculture owes such important improvements, facilitated his researches by procuring him fleeces of Merinos in the grease from animals in health, diseased, and such as had died of the rot.

The wools of the healthy, dead, and diseased animals, corresponding to the numbers $1,2,3$, were employed separately, together, and mixed with scrapings (pelure), wool of very inferior quality, and which has besides been altered by lime.

Scouring and bleaching are so intimately connected with the operations of dyeing, that the author thought fit to begin his comparative observations with these preliminary processes, and even to extend them to the grease, the constituent principles of which were precisely explained in M. Vauquelin's memoir on the nature of that substance.

The agents which he employed for scouring wool, either in the fleece or spun, are: 1. Grease; 2. Soap; 3. Caustic potash ; 4. Hot water; 3. Boiling water; 6. Flanders soap.

1. These wools being treated separately, according to the universal custom, were not completely freed from grease. No. 1. was very white, perfectly free from all impurity, without the smell of sheep; but, on rubbing it between the fingers, a matter sontewhat greasy might be perceived. The wool of the beast No. 2, which had died of the rot, was extremely dirty, charged with earth and animal matters: after being scoured it had still a yellowish gray colour, some smell, and was more greasy than the preceding. In the fleece of No. 3, attacked with a languid disease, were a great quantity of ticks. That insect had not a little contributed to aggravate the disease of the animal, whose soft, weak 
weak wool was of a greenish yellow colour, which distinctly announced its decay.

2. A portion of the wool of each of the preceding numbers, being treated hot with 1-20th of soap, became very white, and perfectly free from the grease: it had a very little smell, which exposure to the air speedily removed.

3. One-fortieth part of caustic potash scours and whitens wool extremely well; but this method, though very efficacious, is attended with too many inconveniences to advise its employment.

4. Wool steeped for some time in hot water lost, by the action of the potash, too little of its greasy matter to be employed in that state.

5. It is dangercus in all the operations of scouring to raise the temperature of the fluid above $60^{\circ}$, or to leave the wool in it longer than a quarter of an hour, for it is liable to be very soon injured in boiling water.

6. Fianders soap is the substance which appeared to act in the most advantageous manner; it scours very speedily, and gives wool a degree of whiteness which it is extremely difficult to produce by any other means.

On comparing wool spun in the grease and afterwards scoured, with that scoured before it was spun, it appeared that the former had become exceedingly white, resembling the colour of unwrought cotton, while the second retained a dull yellow cast, from which it can never be freed. This last experiment frequently repeated, and in several different ways, constantly afforded the same results. It perfectly agrees with the ideas current in the work-shops, that wool badly scoured can never be thoroughly cleansed from grease, and that a great part of the preparations it may receive in dyeing are never fixed in a solid manner. Thus, besides the advantage of sparing proprietors an operation which they never execute perfectly, a twofold cause ought to induce them to preserve wool in the grease: in the first place, to protect it from insects and grubs, which seldom attack it in that state; and in the second, to allow the various arts which employ white wool the means of giving it that purity and lustre which it can never acquire when it has been previously scoured.

The effects of gas and sulphuric acid were likewise tried; but neither of those means was capable of giving to wool, twice scoured, the same degree of whiteness as to that which had been completely freed from grease at once.

These experiments served to ascertain a fact which he 
had long before observed; namely, that whiteness, so far from being the same in substances belonging to different classes, varies even in the produce of the same class : thus, the white of cotton will never be the same as that of thread, and a difference will always be perceived between the whiteness of wool and that of silk, in the same manner as we distinguish, though with greater difficulty, the numerous products of individuals of the same family. For it cannot be doubted that, if even the same disposition of the surfaces could estabiish between all these bodies a certain identity for reflecting the light; yet, as the smallest difference of their nature must affect their affinity, this alone would be sufficient to produce alterations in them.

The intention of these researches was to ascertain the influence which the state of the animal must exercise over the grease, and the nature of the wool.

The grease is a fatty, unctuous substance, with a very strong smell, which is supplied in the sheep by sweat, and the transpirable matter emitted by all animals. When dissolved in water, and filtered to disengage it from the earthy and animal matters which adhere to it, it is of a beautiful yellow fawn colour, more or less inclined to red, and com. posed, according to M. Vauquelin, of a soap with a basis of potash, animal matter, lime, and potash, combined with carbonic, acetic, and muriatic acids. Filtration likewise separates a white matter floating on the surface of the grease, and which in scouring does not combine with the alkalies : it appears to be of the same nature as suet; it melts, and becomes liquid, at a low temperature, and takes fire very easily.

The animal matter dissolved by alkalies is precipitated of a reddish yellow by all the acids. Oxygenated muriatic acid and oxygenated muriatic acid gas form in it a white flaky precipitate, which becomes coloured by exposure to the air : it is a kind of paste, soft, somewhat viscous, of a dirty yellow colour; it speedily becomes liquid, and burns with a bright white flame. This matter, when kept for some hours at eighty degrees, in several pounds of water, is totally insoluble; but by evaporating the liquid you obtain a small quantity of a soft matter, of a dark brown colour, which has an agreeable smell, resembling that of the extract of liquorice. He was the less surprised to find this smell in the grease, as in his experiments made in the year 1800 , by which he first demonstrated the presence of potash in it, he remarked that ammonia, kept in digestion with this substance, gave it a strong smell of orange flowers, 
and that all the antient writers who treat of the medical properties of the asype, and its foetid smell, agree that after a very long period it changes to an agreeable odour, resembling that of ambergris.

Alcohol treated with the animal matter take up a resinous substance of a pale yellow colour, which is precipitated in white flakes, of a light yellow, by water and by acids.

Being desirous of attacking the yellow extremities of the parts of the wool from under the belly and the thighs of the animal, he treated them with alcohol, quicklime, and caustic alkalies; but none of these agents was capable of changing their colour. It appears that the grease accumulated in those parts, together with the action of the air, produces a very intimate combination, which cannot be destroyed without injuring their texture.

Equal portions of the grease, Nos. 1, 2, 8, at the same degree of concentration, were filtered and evaporated nearly to dryness in capsules of porcelain. No. 1 . furnished twice as much matter as the two otbers; it strongly attracted the humidity of the air, and became almost entirely liquefied by it. Acids acted on all three in the same manner, producing a very decisive effervescence. After burning them in a crucible of platina, he separated from all three, by distilled wate or by nitric acid, potash slightly carbonated, or nitrate of potash, the weight of which was more considerable in No. 1. than in 2 and 3, which exhibited no very perceptible difference.

These experiments, by demonstrating that the grease and the potash, one of its component principles, increase or decrease in the Merinos, according to their state of health or of disease, enable us likewise to forn a judgment of the immediate relation of this substance to these different states, as also of its influence on the beauty of their products. For it would be a great mistake to look upon it as prejudicial to them, when we know that the augmentation of this secretion is incapable of altering the health of the animals, as remarked by Messrs. Gillert, Tessier, and Huzard, in their observations on the growth of long wools; and when the most celebrated naturalists agree in rejecting every method tending to deprive them of it, such as exposing them to long rains, and washing their baoks. Besides, does not the Merino, which is the most distinguished of all the species of this genus for the fineness and the beauty of its rich fleece, yield the greatest quantity of grease ? and do we not see this substance diminishing with the quality of the wool, 
and $d$ windling to nothing in those of the same species that are covered with hair, as the sheep of Guinea and Senegal ?

As M. Roard cannot at present give his observations all the latitude of which they are susceptible, he hastens to make public the experiments relative to the effects produced in dyeing by the different qualities of the wools he employed.

The colour assumed by wools while steeping appeared to him a fact so interesting, that he thought it necessary to investigate the cause. He alternately changed the vessels and the agents destined for this operation, and ascertained that this coloration ought to be ascribed entirely to the action of copper; for ammonia forms a blue precipitate in steeping vessels of that metal, while the same precipitate is extremely white, if vessels of earth, porcelain, or even tin, be employed. Wool left for some hours in boiling water, in a copper vessel, acquires a greenish gray tint; but this effect is greatly augmented by the ordinary mixture of alum and tartar. If into this bath, saturated and boiling, you plunge different kinds of combed wool, those produced by the native breed of France and Holland assume a lively green colour, and those of Merinos a greenish yellow, or a very dark ochre yellow. Though this effect is much less perceptible in steeps on a large scale, yet, by comparing white wool with that which has been steeped, the difference appears sufficiently striking. The colour fixed by this method is very little altered by alkalies, and not at all by acids, which in a slight degree heighten its intensity : ammonia turns it to a yellowish gray.

In these experiments the author employed alum manufactured by M. Curaudau, which appeared to him to possess all the qualities and defects of Roman alum, in a comparative investigation which he undertook relative to the effects in dyeing af all the kinds sold in the shops.

The wools, after remaining eight days in the alum liquor, were then dyed with cochineal, madder, saunders wood, \&c. The same qualities, whether natural or acquired, having appeared to act in the same manner in all the experiments to which they were subjected, $M$. Roard describes only the first, which was that made with cochineal.

Experiment I.

No. 1. Healthy Merinos.

A beautiful carnation red, inclining a bittle to yellow. This No. 1. surpassed in depth and intensity all the shades which he tried of more than two or three calours.

Experiment 
Experiment II.

Nos. 2 and 3. Animals dead and diseased.

The colours almost always the same; sometimes, however, No. 3 is less highly coloured. The difference between these wools of dead and diseased animals and those of healthy sheep, though both of the same flock, is very remarkable.

Experiment III.

No. 4. A Mixture of equal Parts of 1,2 , and 3.

The quantity of the altered wool being much greater in this experiment, the colours I obtained with it nearly resemble those of 2 and 3 , but never equal in beauty that of No. 1 .

Experiment IV.

No. 5. The same Wool as No. 1, but spun without Oil, and cleared of the Grease at a single Operation.

The colour produced by this wool was more brilliant than that of No. 1, but its tone was less high ; which demonstrates that in some operations the natural colouring matter must be of some utility. Thus, in fine crimsons, and some other colours, the silks ought to retain somewhat of their rawness, for those that are white can never acquire the same appearance. This observation perfectly coincides with the experiments of Coulomb on the good effects in dyeing of silk still charged with a portion of its colouring principle.

\section{Experiment $\mathrm{V}$.}

No. 6. Clippings of Wool of Picardy.

The deteriorated matter, which forms a part of this wool, takes the colour so ill, that it is always clouded : in all the experiments it invariably produced a dull dirty colour, far inferior to that of No. 1. By the mixture of this damaged wool, the dealers adulterate the quality of all the carded wools of France, which, as much preparation agrees very ill with them, can be employed only in the manufacture of the most ordinary stuffs.

\section{Experiment VI.}

No. 7. Clippings and Wool of the Merinos No. 1, in equal Parts.

Notwithstanding the bad quality of the wool No.6, this mixture took the colour so well, that, in all my experiments, it was not much inferior to that of No. 1, though, owing to the clippings, its appearance was always dull. 
Experiment VII.

Nos. 8 and 9. Mixtures made with equal Parts of Clippings, the Wool of deal Animals No. 2, and of distased Sheep No. 3.

The difference betwcen Nas. 8 and 9 was scarcely perceptible; the colours were dull and dirty, and darker than Nos. 2 and 3 , of which they were in part formed.

\section{Experiment VIIJ.}

The same numbers of wool employed in the preceding experiments were dyed blue, and their results perfectiy agreed with those already stated. This colour is perhaps the only one that wools of an inferior quality take well, though the blue is not equal, and always inclines to black.

\section{Experiment IX.}

The wools Nos. 1 and 2 , which had been scoured, and the scrapings, No. 8, were treated with the dye, comparatively with that of No. 1, spun in the grease. The three first took the colour slowly, and assumed a dull blue tint, inclining to black. No. 1 , on the contrary, took it very speedily, and acquired a beautiful and very deep blue colour. These four numbers were scoured together, hot, with Flanders soap: the wools of the bealthy and dead animals, and the clippings, entirely lost their colour; while that of No. 1, in the grease, retained a very brilliant barbel blues.

Experiment X.

Wools of the three qualities employed in the three manufactories of tapestry were dyed at the same time with the Merino wool No. 1. In all the experiments the latter took a deeper colour than any of the others; which are carded wools of Flanders, Holland; and Picardy.

The principal facts contained in this memoir lead to the following consequences :

1. In scouring, the beat of the fluid ought never to exceed $60^{\circ}$; for, even before it rises to the temperature of boiling water, wools in the grease are very hable to be injured by the potash.

2. Wools scourcd at two operations can never be rendered completcly white. This effect seems to proceed from a change of state in the greasy colouring matter, which, by becoming more highly uxygcnated, loses its solubility.

3. Oxygenated nuturiatic acid, and oxvgenated muriatic acid gas, precipitate, in white flakes, the animal matter contained in the grease: it is speedily coloured by the ait, Vol. 23. No. 89. Oct. 1805. 
and contains a substance with an agreeable smell, which appears to be perfectly analogous to that developed by ammonia, and with that discovered in it by the antients.

4. It ought to excite little surprise to see the quantity. of potash and of grease diminish or increase in sheep according to their state of discase or of health; for a secretion so complicated, requiring the utmost exertions of nature, must invariably be intimately connected with the augmentation or diminution of the vital powers. But how is it possible to doubt that the grease has an immediate action on the quality of the wool, when we see those two substances proceed, if we may so express it, in harmony, from the wild sheep of Greece to the most beautiful and the most vigorous Merinos? It was probably to assist them to recover this precious transpiration, that the Romans, after shearing, covered them with a mixture of tonic and oily substances, which, according to Columella, preserved them from many diseases, and contributed to render their wools finer and longer.

5. These wools constantly assume, in copper vessels, solid colours, more or less deep, which, even at the lowest degree of coloration, prevent them from taking the first shades of a tint. This effect is obviated by the use of tin vessels, the oxide of which cannot alter the whiteness of the wool during steeping.

6. All the experiments prove that the affinity for the colouring matter varies in wools according to the healthy or diseased state of the animal ; and that the wool of healthy Merinos is always more highty coloured than not only Nos. 2 and 3 , though the produce of the same flock, but even than all the carded wools of France and Holland. They show to what causes we ought to ascribe the effects produced on wools the exterior characters of which are perfectly alike, and which, after receiving the same preparations, assume, in the same vat, different colours.

7. The beautiful and very solid blue colours obtained from wools in the grease, demonstrate, in a very positive manner, the influence of that animal matter, which, if transferred to other substances, might furnish the arts with many highly useful applicatious.

\section{Olservations of the Author.}

Since the reading of my memoir to the National Institute, I have received a complete proof of the facts to which $I$ ascribe the variations exhibited in dyeing by carded wools. Having ascertained that the different causes which exercised 
an influence over our operations could not arise from the manipulations of the dyer, we complained to our woolmerchant of the bad quality of his goods. He was then obliged to acknowledge that he mixed the wools of Flanders with those of Holland according to the general practice of the trade; and that, though all the dyers had constantly complained of the same defects, yet, as they had neglected to acquaint him with the cause, he had not been able to take such measures as to prevent them in future. These wools are likewise attended with a disadvantage of another kind, which it is of considerable importance to indicate; I mean the augmentation that is given them by passing them through butter-milk, and which almost always amounts to one-eighth of their weight. They are surcharged with a white dusty matter; which, even after careful and repeated washing, still furnishés a sufficient quantity of acetous acid to change a great number of results. in dyeing.

VIII. New Galvanic Discoveries. By M. RrTTer. Fxiracted from a Letter from M. CHRIST. BERNOULLi*.

\section{Charging a Louis d'Or by the Pile.}

$\mathrm{T}$ TyE pile with which M. Ritter commonly performs his experiments consists of 100 pairs of plates of metal, two inches in diameter; the pieces of zine have a rim to prevent the liquid pressed out from flowing away; and the apparatus is insulated by several plates of glass.

As M. Ritter resides at present near Jene, I have not had an opportunity of seeing experiments with his great battery of two thousand pieces, or with his baitery of fifty pieces, each thirty-six inches square, the action of which continues very perceptible for a fortnight. Neither have I seen his experiments with the new battery of his invention, consisting of a single metal, and which he calls the charging pile.

I have, however, seen him galvanize a louis d'or. He places it between two pieces of pasteboard, thoronghly wetted, and keeps it six or eight minutes in the chain of circulation connected with the pile; and thus the louis becomes charged, though not immediately in contact with the conducting wires. If the louis thus charged be applied to the crural nerves of a frog recently prepared, the usual con-

* Abridged from Van Mons's Journal, vol. vi. 